and adoption societies, and this downward trend has continued. This means that large numbers of couples wishing to create a family by adoption have been, or are going to be disappointed. The Adoption Resource Exchange co-ordinates some 50 adoption agencies in home-finding for coloured and older children and those with medical problems. We also deal with many hundreds of inquiries from the public each year, and are only too aware of the frustration and pain which childless couples are suffering in their search for a baby.

On learning of their infertility many couples turn immediately to adoption before they have had time to think through or discuss what either childlessness or adoption will mean to them. Naturally many doctors suggest adoption to ease the distress occasioned by a diagnosis of infertility. Workers in the adoption field recognize that the position should be much better known to all concerned, so that an already distressing situation is not made worse by the constant dashing of hope as application after application to adoption agencies is turned down. Because of the very small numbers of babies they are asked to place, most adoption agencies have closed their lists and reopen them only periodically to people within their own area. Many applicants suffer the frustrating experience of writing to 20 or 30 such agencies. We know from public meetings that "getting on a list" can become almost an aim in itself, obscuring a full appreciation of the adoption of a child, with all that that entails. Had such couples taken time to consider all aspects of their situation instead of turning first to adoption, some might well have decided that adoption was not really appropriate for them and that life could have other compensations to offer.

At present, many couples are being rejected by adoption agencies simply because there are fewer babies being offered than there are homes wanting them. All doctors should be aware of this. We should perhaps add that there are still often children past the infant stage who need adoptive homes. If any family feels able to consider a child partially or fully of Negro origin, an older child (four or five years and upwards), a handicapped child, or brothers and sisters who need to be kept together we are always very glad to hear from them. Adopters of such children may well be couples with children already rather than childless couples longing for a baby.

We hope that fuller information on the adoption situation as it now is will enable doctors, gynaecologists, and all who deal with in-fertile couples to advise them better about adoption and to indicate to them that unfortunately many may be disappointed.We are, etc.,

PHILlIDA SAWBRIDGe WANDA MCCLANAHAN Organising Secretaries,
on Resource Exchange Cranmer House, 39 Brixton Road,
London S.W.9.

\section{Seat Belt Syndrome}

SiR,-There is no doubt that correctly fitted and properly worn seat belts markedly reduce the incidence of serious and fatal injuries in road traffic accidents. It is perhaps less well known that seat belts may them- selves on occasion be the cause of injury, and though such injuries are usually minor, they are in almost $1 \%$ of cases serious and then they tend to follow a definite and to some extent predictable pattern. It is certainly important that medical staff responsible for the primary care of road acciden victims should be aware of this "seat bel syndrome."'

One particular group of seat belt injuries which deserves special emphasis is the combination of severe injury to both the fixed part of the descending colon and the proximal jejunum with flexion injury of the lumbar spine." That this distinctive triad of injuries is important is witnessed by the relative frequency with which it occursindeed $30 \%$ of seat belt injuries to the jejunum coexist with damage to both the left colon and the lumbar spine, 50\%, of such jejunal injuries are associated with an injury to the left colon, and in $15 \%$ o patients sustaining a seat belt flexion injury of the lumbar spine a closed injury of either the left colon or the jejunum is found to be present too. ${ }^{3}$

It is clear that when a patient presents with one of these three injuries a most careful search must be made for the other members of the triad, neither of which may be clinically obvious early on, particularly in the case of an injury to the left colon where the basic lesion is commonly an ischaemic one and delayed perforation with faecal peritonitis the possible result of a missed diagnosis.' One helpful physical sign which may indicate the presence of intra-abdominal in jury is evidence of contusion of the anterior abdominal wall due to the seat belt, particularly where disruption of the recti has occurred, as these tend only to occur when the impact has been severe and therefore when internal injury is more likely. ${ }^{5}-\mathrm{I}$ am, etc.

Broadgreen Hospital,

JOHN SHENNAN

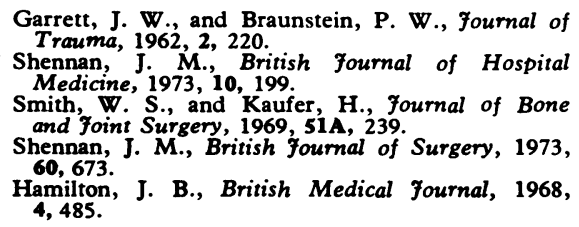

\section{Think Again on Salmon}

SIR,-Your leading article (27 October, p. 186) prompts me to put forward my views on this subject.

In this part of the world our nurses, both senior and junior, are as devoted and intelligent as any we have ever had. Our regional board and management committee tell us we have more nurses than we have ever had. There are certainly more domestic and ancillary staff than we have ever had. In spite of these facts, every doctor to whom I have spoken on this subject confirms my impression that the nursing of patients has deteriorated recently in a manner that is verging on the catastrophic. These contradictory observations require some explanation.

One of the unforeseen results of Salmon has been to deprive the ward sister of ultimate responsibility for her ward. She is now responsible for the ward for the $\mathbf{4 0}$ hours a week that she is on duty, except when she is at a conference, a meeting, or on holiday She no longer feels that what happens in her absence is anything to do with her, and indeed, she is not encouraged to be so concerned. A visit to a ward with seriously ill patients on it at a time when no no. 6 is on duty can be alarming. Not infrequently one finds a third-year nurse or state enrolled nurse who prior to taking charge of the ward has never seen it. She may have arrived on the ward only in time to serve suppers, and no one has taken her round to see the patients or explain the worrying problems to her. I am not referring to an solated incident, but a regular practice. Such occurrences are only to be expected, as a no. 7,8 , or 9 could not possibly be aware personally of all the patients supposedly under her care, and the ward sister no longer has any responsibility to arrange cover for the ward in her absence. We are faced now frequently with the position in which an experienced specialized sister, previously in charge of an intensive care unit, an operating theatre, or a ward, suddenly finds herself under the orders of a no. 8 who is probably equally distinguished in a quite different field and knows nothing about the specialty concerned and whose only qualification to take charge is a training in management. It is as if an E.N.T. surgeon, after attending a management course, was considered suitable to take clinical charge of the orthopaedic or gynaecological departments.

Salmon has been pushed through against the opposition of the whole medical profession without adequate review of it on trial and with no mechanism under the Cogwheel whereby we can criticize or amend it. It is applied without any attempt to recognize the specialization that has appeared in nursing to parallel the specialization in medicine. The appointment of no. $8 \mathrm{~s}$ will lead many of our most experienced and valuable specialized departmental sisters to resign, and unless we can get the Ministry to think again on this subject and consult with the medical profession, we shall very rapidly reach the stage in which all nursing will be carried out by S.E.N.s, orderlies, and ward clerks, while the fully trained S.R.N.S will occupy themselves by adding to the number of administrators that already burden us.

At no point in the Cogwheel scheme is any provision made for medical staff to be consulted about the implementation of Salmon. If the consultant staff of the hospital made far-reaching changes in the method of running the wards and other departments without any consultation with their junior staff, nursing staff, or ancillary staff, they would very rightly forfeit any hope of co-operation that they might other wise have had. We now find senior administrative nursing officers introducing changes under Salmon that very markedly affect the whole of our work and life in the hospital without showing any desire to hear our views or discuss these changes with us, and the mechanism set up under Cogwheel offers us no opportunity even of commenting on them. Let it never be said that we did not warn the Ministry and the Royal College of Nursing of the likely effect of the implementation of Salmon on the welfare of our patients.-I am, etc.,

LESLIE J. TEMPLE

iverpool Cardio-Thoracic Surgical Centre,

Liverpool Cardio-Thoracic Surgica 